\title{
ISSN 1414-6509 \\ Implantação da Companhia Siderúrgica UBU: Avaliação de Impacto a partir da Matriz Insumo-Produto do Espírito Santo
}

\author{
Celso Bissoli Sessa \\ Professor Adjunto do Departamento de Economia da Universidade Federal do Espírito Santo. \\ Endereço: Av. Fernando Ferrari, 514, Goiabeiras. Vitória/ES. Sala 113, Departamento de Economia (DE). \\ CEP: 29075-910. E-mail: celso.sessa@ufes.br
}

\begin{abstract}
Angela Maria Morandi
Professora aposentada do Departamento de Economia da Universidade Federal do Espírito Santo. Endereço: Rua Tupinambás, 752/401, Jardim da Penha, Vitória/ES

CEP: 29060-810. E-mail: ammorandi@gmail.com

\author{
Lorena Zardo Trindade \\ Pesquisadora no Herman Deleeck Centre for Social Policy, Universidade da Antuérpia \\ Endereço: Sint Jacobstraat, 2, S.M. 171, Antuérpia, Belgium \\ CEP: 2000. E-mail: Lorena.ZardoTrindade@uantwerpen.be
}

\section{Leandro de Souza Lino}

Rua Dr Antonio Basílio, 808, B1 E, Apto 301, Jardim da Penha, Vitória-ES

CEP: 29.060-390. E-mail: 1slino@gmail.com

\section{Orlando Caliman}

Diretor da Futura Pesquisa e Consultoria

Endereço: Rua Carlos Eduardo Monteiro Lemos, 262. Shopping Jardins, Salas 207, 209 e 210. Jardim da Penha, Vitória/ES

CEP: 29060-120. E-mail: caliman@ futuranet.ws

Recebido em 11 de março de 2016. Aceito em 16 de março de 2017.

\section{RESUMO}

O objetivo deste artigo é mensurar os impactos socioeconômicos da Companhia Siderúrgica UBU - CSU, um projeto de siderúrgica integrada para produção de 5 milhões de toneladas/ano de placas, em Anchieta, no litoral sul do Espírito Santo. Dada a dimensão do projeto, tanto na fase de construção quanto na de operação, e considerando a infraestrutura a ele vinculada, seus impactos provocarão alterações na estrutura produtiva, na geração e composição do PIB e no perfil do emprego e da renda. A finalidade dessa abordagem é fortalecer os argumentos em torno de uma agenda econômica positiva, já que uma nova siderúrgica, atrelada a um porto e a ferrovias, se apresenta como um fator novo e agregador de capacidade competitiva sistêmica para a economia capixaba.

PALAVRAS-CHAVE: Matriz Insumo-Produto. Economia Capixaba. Siderurgia.

\begin{abstract}
:
The purpose of this article is to measure the socio-economic impacts of Companhia Siderúrgica UBU - CSU an integrated steel project for production of 5 million tons / year of plates in Anchieta, on the south coast of Espírito Santo. Given the size of the project, both in construction and in operation, and considering the infrastructure related thereto, its impacts will entail changes in the production structure, the generation and GDP composition and profile of employment and
\end{abstract}

RE\&D Econ. e Desenv., Santa Maria, vol. 28, n.2, p. 434 - 452, jul. - dez. 2016 
income. The purpose of this approach is to strengthen the arguments around a positive economic agenda, since a new steel, linked to a port and railways, is presented as a new factor aggregator of systemic competitiveness for the state economy.

KEYWORDS: Input-Output Matrix. Capixaba economy. Steel.

\section{Introdução}

Embora o aço seja conhecido desde a antiguidade, a ampliação da escala de sua produção e a difusão de seu uso somente ocorreram com as inovações tecnológicas introduzidas por volta de 1860 nos países industrializados e em fase de industrialização, como Inglaterra, Estados Unidos da América, Alemanha e França. Posteriormente, outros países, como Itália, Japão e Rússia, passaram também a se preocupar em implantar suas próprias usinas siderúrgicas. E foram justamente esses países que se tornaram industrializados, com uma estrutura produtiva integrada, e passaram a comandar os avanços do desenvolvimento do capitalismo em nível mundial. O aço é considerado um fator chave da Segunda Revolução Industrial, uma vez que abriu novas possibilidades para os processos produtivos, permitindo criar e consolidar novos produtos e mercados, além da produção em larga escala em muitos setores industriais (MORANDI, 1997).

Com efeito, alguns indicadores da indústria siderúrgica, tais como o consumo per capita de aço e a intensidade do consumo de aço em relação ao PIB, são utilizados para indicar o nível de desenvolvimento industrial de um país. Por outro lado, a evolução da produção mundial de aço e sua distribuição regional (continentes, grupos de países, etc.) foram bastante modificadas ao longo do Século XX. O Brasil ingressou efetivamente na era do aço durante a Segunda Guerra Mundial, com o início da construção da Companhia Siderúrgica Nacional, em 1941, e sua inauguração em 1946. O núcleo básico da siderurgia brasileira foi comandado pelo governo federal, seja por investimentos diretos, seja como participante de joint ventures com capitais externos. Ressalta-se o zelo para com o planejamento do setor que, desde o início, visava a criar autonomia em relação às importações e, posteriormente, contribuir com saldos positivos na balança comercial (MORANDI, 1997).

Aliás, a participação estatal na formação das indústrias siderúrgicas foi uma política que se manifestou em nível mundial, independentemente do desenvolvimento das economias e das particularidades das intervenções em cada país. Por sua importância na integração da estrutura industrial, como fornecedora de bens intermediários para os setores de bens de capital, de bens de consumo duráveis e da infraestrutura, a siderurgia chega a ser considerada uma indústria ligada à segurança nacional. Os Estados Nacionais sempre tiveram um papel fundamental no planejamento da indústria siderúrgica, desde a concepção das usinas, até como participantes ativos no aporte dos recursos financeiros necessários aos investimentos. A fraca participação histórica do capital privado nesse 
setor se justifica pelo elevado capital inicial e pelo longo prazo de instalação, de maturação e do retorno dos investimentos (DE PAULA, 2010).

Desde 1940, o aço tem sido de vital importância para a economia brasileira. Por aproximadamente 50 anos, o governo brasileiro manteve um monopólio sobre o setor de produção de aços planos. No setor de produção de aços não-planos, tradicionalmente composto por companhias privadas de pequeno porte, o governo brasileiro não possuía o monopólio do setor. Durante a década de 1970, investimentos governamentais consideráveis foram realizados para propiciar ao Brasil uma indústria siderúrgica capaz de abastecer o processo de industrialização do país. Após uma década de praticamente nenhum investimento no setor, o governo selecionou o setor siderúrgico como o primeiro setor para o processo de privatização iniciado em 1991 (OLIVEIRA, 2007).

A principal característica da indústria siderúrgica é a grande movimentação de materiais, sejam de matérias-primas sejam de seus produtos acabados. Sendo assim, a logística de transporte concernente a uma usina constitui um dos principais fatores de sua competitividade no mercado internacional. Outra importante fonte de competitividade é sua localização em relação aos fornecedores das principais matérias primas - o minério de ferro e o carvão metalúrgico - e aos seus principais clientes. Raramente encontra-se um espaço (país ou região) que tenha uma proximidade razoável dos três componentes em simultâneo - minério de ferro, carvão metalúrgico e mercado consumidor. Neste aspecto, o Espírito Santo se apresenta como um espaço privilegiado para a instalação de usinas siderúrgicas, pois, mesmo não dispondo em seu território das matérias-primas e tampouco de um mercado consumidor de aço, está localizado muito próximo das minas de minério de ferro, transportado por uma eficiente ferrovia, como dispõe de uma costa propícia para a instalação de portos com capacidade razoável para atender uma siderúrgica. O Espírito Santo, embora apresente um baixo consumo interno de aço em sua estrutura produtiva - especialmente por não possuir um setor desenvolvido ligado aos bens de consumo duráveis e de produção de bens de capital - é um espaço privilegiado para a instalação de usinas siderúrgicas. Além disso, o Espírito Santo é um grande fornecedor de calcário, outro importante insumo para uma usina siderúrgica (MORANDI, 1997).

Desde o início do Século XX já se cogitava a possibilidade de se criar um "corredor siderúrgico" que ligasse as minas de minério de ferro de Minas Gerais a Tubarão. De possuidor de vantagens naturais, como o litoral de águas profundas e uma posição central no litoral brasileiro, o Espírito Santo passou a se aproveitar, gradativamente, dessas vantagens construindo uma infraestrutura propícia ao desenvolvimento de um verdadeiro cluster mínero-siderúrgico, que é, sem dúvida, o principal da economia capixaba (MORANDI, 1997).

Econ. e Desenv., Santa Maria, vol. 28, n.2, p. 434 - 452, jul. - dez. 2016 


\section{O Modelo Insumo-Produto}

Uma matriz de insumo-produto, inicialmente desenvolvida por Wassily Leontief, constitui um quadro de dupla entrada, em que uma registra os insumos utilizados pelas atividades econômicas e a outra o destino das produções. Desta forma, possibilita a percepção da interdependência entre os setores (KURESKI; NUÑEZ; RODRIGUES, 2007).

Conforme Feijó e Ramos (2007), o modelo proposto por Leontief utiliza os fluxos entre as diferentes atividades econômicas, cuja base de dados necessária para descrever as relações entre si e com a demanda final é composta pela formação bruta de capital fixo (I), exportações (X), variação de estoques (VE), consumo do governo (G) e consumo pessoal (CF), sua conta de renda e as importações (M). Desta forma, sua base de dados é uma Tabela de Transações, com a descrição dos fluxos monetários entre as diversas atividades e a demanda final. Ela também apresenta as importações e o valor adicionado para cada uma das atividades produtivas, detalhando em salários, impostos e subsídios e o excedente (FEIJÓ; RAMOS, 2007).

O modelo é dividido em três setores (agricultura, indústria e serviços), obtendo para cada um deles o consumo intermediário, a demanda final e o valor bruto da produção. Cabe destacar que subtraindo-se o valor bruto da produção do consumo intermediário tem-se o valor adicionado (KURESKI; NUÑEZ; RODRIGUES, 2007). Na linha para a agricultura, tem-se que o valor bruto da produção da agricultura é $X_{1}$, a demanda intermediária é $x_{11}, x_{12}$ e $x_{13}$, e a demanda final é $Y_{1}$. Ressalta-se que a diferença entre o valor bruto da produção e a soma da demanda intermediária é igual ao valor adicionado, sendo este utilizado para a remuneração dos fatores de produção. Este mesmo raciocínio é utilizado para as outras duas atividades apresentadas na figura 2.1. E com a soma do valor adicionado das três atividades tem-se o Produto Nacional da economia. $\mathrm{O}$ valor adicionado é dividido entre as remunerações dos fatores de produção como salários, aluguéis, lucros e juros. E o somatório desses fatores resulta na Renda Nacional do país. Com o somatório da demanda final, tem-se o Dispêndio Nacional do país (KURESKI; NUÑEZ; RODRIGUES, 2007).

\begin{tabular}{|l|c|c|c|c|c|}
\hline \multirow{2}{*}{ Atividades } & \multicolumn{3}{|c|}{ Demanda intermediária } & $\begin{array}{c}\text { Total da } \\
\text { demanda } \\
\text { final }\end{array}$ & $\begin{array}{c}\text { Valor bruto } \\
\text { da produção }\end{array}$ \\
\cline { 2 - 4 } & Agricultura (1) & Indústria (2) & Serviços (3) & $Y_{1}$ & $X_{1}$ \\
\hline Agricultura (1) & $x_{11}$ & $x_{12}$ & $x_{13}$ & $Y_{2}$ & $X_{2}$ \\
\hline Indústria (2) & $x_{21}$ & $x_{22}$ & $x_{23}$ & $Y_{3}$ & $X_{3}$ \\
\hline Serviços (3) & $x_{31}$ & $x_{32}$ & $x_{33}$ & \multicolumn{2}{|c}{} \\
\hline Valor adicionado & $Z_{1}$ & $Z_{2}$ & $Z_{3}$ & \multicolumn{2}{|c}{} \\
\hline Valor bruto da produção & $X_{1}$ & $X_{2}$ & $X_{3}$ & \multicolumn{2}{c}{} \\
\cline { 1 - 4 } & & &
\end{tabular}

Figura 2.1 - Fluxo de bens por setores de origem e destino em termos simbólicos

Fonte: Kureski, Nuñez e Rodrigues (2007) 
Conforme Kureski, Nuñes e Rodrigues (2007), os coeficientes técnicos são definidos como as necessidades diretas de insumos dos diversos setores, ou pelas relações intra e interindustriais diretas, e são calculados pela seguinte fórmula:

Onde:

$$
a_{i j}=\frac{X_{i j}}{X_{j}}
$$

$$
\begin{aligned}
& a_{i j}=\text { coeficiente técnico; } \\
& X_{i j}=\text { consumo intermediário; } \\
& X_{j}=\text { valor da produção. }
\end{aligned}
$$

Assim, com o aumento da demanda final, ocorre não somente os efeitos diretos na produção de insumos, mas também os efeitos indiretos, ou seja, os impactos diretos e indiretos de um aumento unitário da produção da atividade ${ }^{j}$ sobre a produção de ${ }^{i}$. Desta forma, seguindo o exposto na figura 2.1, o valor bruto da produção $X_{i}$ é representado pelas seguintes fórmulas:

$$
\begin{aligned}
& X_{1}=x_{11}+x_{12}+x_{13}+Y_{1} \\
& X_{2}=x_{21}+x_{22}+x_{23}+Y_{2} \\
& X_{3}=x_{31}+x_{32}+x_{33}+Y_{3}
\end{aligned}
$$

Pela equação (1), tem-se o valor do insumo igual a:

$$
X_{i j}=a_{i j} X_{j}
$$

Substituindo (3) em (2), tem-se:

$$
\begin{aligned}
& X_{1}=a_{11} X_{1}+a_{12} X_{2}+a_{13} X_{3}+Y_{1} \\
& X_{2}=a_{21} X_{1}+a_{22} X_{2}+a_{23} X_{3}+Y_{2} \\
& X_{3}=a_{31} X_{1}+a_{32} X_{2}+a_{33} X_{3}+Y_{3}
\end{aligned}
$$

Em forma de matriz, a fórmula (4) pode ser:

$$
X=A X+Y
$$

Onde:

$X$ = vetor-coluna do valor bruto da produção;

$A=$ matriz dos coeficientes técnicos;

$Y=$ vetor-coluna do valor da demanda final.

Isolando $Y_{i}$ da equação (4), tem-se:

$$
\begin{aligned}
& \left(1-a_{11}\right) X_{1}-a_{12} X_{2}-a_{13} X_{3}=Y_{1} \\
& -a_{21} X_{1}+\left(1-a_{22}\right) X_{2}-a_{23} X_{3}=Y_{2} \\
& -a_{31} X_{1}-a_{32} X_{2}+\left(1-a_{33}\right) X_{3}=Y_{3}
\end{aligned}
$$

Econ. e Desenv., Santa Maria, vol. 28, n.2, p. 434 - 452, jul. - dez. 2016 
E na forma de matriz, a equação (6) pode ser representada por:

$$
(I-A) X=Y
$$

Em que:

$$
\begin{aligned}
& I=\text { matriz identidade; } \\
& A=\text { matriz dos coeficientes técnicos; } \\
& X=\text { vetor-coluna do valor bruto da produção; } \\
& Y=\text { vetor-coluna do valor da demanda final. }
\end{aligned}
$$

Para que seja possível obter os objetivos da Matriz Insumo-Produto, ou seja, determinar os efeitos diretos e indiretos resultantes do aumento de uma unidade monetária na demanda final ( ${ }^{Y}$ ), é necessário isolar o valor bruto da produção da equação (7), assim:

$$
X=(I-A)^{-1} Y
$$

Onde:

$$
\begin{aligned}
& X=\text { valor bruto da produção; } \\
& (I-A)^{-1}=\text { matriz de Leontief; } \\
& Y=\text { demanda final. }
\end{aligned}
$$

Para que o comportamento do sistema econômico possa ser tratado no modelo desenvolvido por Leontief, são adotadas duas hipóteses que Feijó e Ramos (2004) resumem em: a) homogeneidade, cada produto é fornecido por uma única atividade, com rendimento constante de escala (somente uma única tecnologia é empregada na produção de um produto); e b) proporcionalidade, os insumos consumidos em cada atividade são função somente do nível de produção da respectiva atividade.

Além disso, do cálculo para obtenção da Matriz Insumo-Produto derivam-se os multiplicadores de impactos que, conforme ressaltam Feijó e Ramos (2007, p. 314), "adicionam novas informações à análise de insumo-produto ao incorporar os componentes do valor adicionado à equação básica do modelo [...]”. Os dois principais multiplicadores são: i) multiplicador direto, que mede o impacto sobre uma variável da conta de renda a partir de um aumento unitário da demanda final de uma determinada atividade, considerando apenas as atividades que fornecem insumos diretamente a esta atividade; e ii) multiplicador total (direto mais indireto), que mede o impacto sobre uma variável da conta de renda a partir de um aumento unitário da demanda final de uma determinada atividade, considerando todas as atividades que fornecem insumos, direta e indiretamente a essa atividade.

RE\&D Econ. e Desenv., Santa Maria, vol. 28, n.2, p. 434 - 452, jul. - dez. 2016 


\subsection{O Modelo MIP para o Espírito Santo}

A matriz Insumo-Produto do Espírito Santo de 2003 busca analisar a relação interregional do Espírito Santo e é dividida em 36 setores, conforme demonstrado na Tabela 2.1 .

Tabela 2.1 - 36 setores da Matriz Insumo-Produto Interregional do Espírito Santo

\begin{tabular}{ll}
\hline & Setores \\
\hline 1. Agropecuária & 19. Ind. alimentícia, bebidas, fumo e biocombustíveis \\
2. Extrativa mineral & 20. Madeira, mobiliário e indústrias diversas \\
3. Extração de petróleo e gás & 21. Energia elétrica (produção e distribuição) \\
4. Produtos de minerais não-metálicos & 22. Gás encanado (produção e distribuição) \\
5. Metalurgia básica & 23. Água e saneamento \\
6. Outros metalúrgicos & 24. Construção civil \\
7. Máquinas e equipamentos & 25. Comércio \\
8. Material elétrico & 26. Serviços de transporte rodoviário \\
9. Equipamentos eletrônicos & 27. Serviços de transporte ferroviário \\
10. Automóveis, caminhões e ônibus & 28. Serviços de transporte aéreo \\
11. Autopeças e outros veículos & 29. Serviços de transporte - outros modais \\
12. Celulose, papel e gráfica & 30. Serviços de comunicações \\
13. Produtos da borracha e artigos plásticos & 31. Instituições financeiras \\
14. Elementos químicos, farm. e veterinários & 32. Serviços prestados às famílias \\
15. Refino do petróleo & 33. Serviços prestados às empresas \\
16. Têxtil & 34. Aluguel de imóveis \\
17. Vestuário & 35. Administração pública \\
18. Calçados & 36. Serviços privados não-mercantis \\
\hline
\end{tabular}

Fonte: Elaboração própria.

As estimativas de emprego e salários basearam-se nos dados do Cadastro Central de Empresas (Cempre), do Instituto Brasileiro de Geografia e Estatística (IBGE), que reúne informações anuais da instituição nas áreas de indústria, construção, comércio e serviços, além dos dados da Relação Anual de Informações Sociais - RAIS. Cabe destacar que tanto no caso das informações sobre emprego quanto no de finanças utilizou-se os dados para o ano de 2003 para coincidir com os dados da matriz e a situação em que se encontrava a economia naquele período.

Nas estimativas considerou-se que a economia capixaba permaneceu estática em 2003, sendo as oscilações oriundas apenas dos impactos diretos e indiretos da CSU. Além disso, os preços foram inflacionados pelo IGP-DI para janeiro de 2010. Para a fase de implantação, as simulações foram realizadas conforme as demandas por insumos nos três anos, enquanto para a de operação considerou-se que a empresa atuará com $85 \%$ de sua capacidade instalada no primeiro ano e $100 \%$ no segundo.

Ressalta-se, ainda, que foram estimados dois cenários: um cenário base e outro agressivo. No primeiro considerou-se a capacidade atual que a estrutura produtiva existente, estadual e nacional, já possui para interagir com o Projeto CSU, seja para compras, seja para vendas. No segundo cenário foi considerada a possibilidade da ampliação dessa capacidade de interação com esse empreendimento, ressaltando-se que os impactos no cenário agressivo são bem expressivos para a economia capixaba em

Econ. e Desenv., Santa Maria, vol. 28, n.2, p. 434 - 452, jul. - dez. 2016

RE\&D 
relação à brasileira, haja vista que esta dispõe de uma estrutura produtiva muito mais complexa e completa, enquanto a economia capixaba teria que produzir avanços em sua estrutura atual no sentido de, de um lado, ampliar sua capacidade de oferta a uma siderúrgica e, de outro, encontrar novas oportunidades nas compras dos produtos e coprodutos gerados por este projeto.

\section{Caracterização Socioeconômica}

\subsection{Nível de Atividade}

De acordo com os dados da tabela 3.1, em 2007, o valor corrente do Produto Interno Bruto (PIB) do Espírito Santo saltou de R\$ 26,7 bilhões em 2002 para R\$ 60,3 bilhões em 2007. Desde 2002, nova base das Contas Regionais, o crescimento acumulado no estado foi de $29,7 \%$, o que corresponde à média anual de 5,3\%. No Brasil, esse crescimento foi de $21,7 \%$, ou de $4,0 \%$ na média anual. Estes números refletem um possível cenário de crescimento potencial elevado no longo prazo.

As atividades primárias e secundárias são relativamente importantes na economia capixaba e a cada ano vêm ampliando ainda mais essa importância relativa. As atividades secundárias tiveram variação real de 13,3\%, com participação de 34,5\% no Valor Adicionado do estado. A indústria apresentou crescimento de 14,5\% em 2007, sendo 29,4\% na Extrativa Mineral e 4,4\% na Transformação. Esta última apresentou crescimento significativo, da ordem de 4,4\% em 2007, com maior peso para a metalurgia básica $(9,4 \%)$. O setor de Serviços, com participação de 56,3\% no valor adicionado do estado, apresentou crescimento de $5,1 \%$. As maiores contribuições relativas no resultado das atividades terciárias vieram do Comércio e Serviços de Manutenção e Reparação (6,3\%), Intermediação Financeira (18,5\%) e Transportes (3,7\%). Os Serviços Prestados às Empresas também tiveram crescimento real elevado $(10,9)$.

Tabela 3.1: Composição do PIB do Espírito Santo, 2002-2007 (milhões de reais)

\begin{tabular}{ccccc}
\hline ANO & $\begin{array}{c}\text { Valor adicionado bruto a } \\
\text { preço básico corrente }\end{array}$ & $\begin{array}{c}\text { Impostos sobre } \\
\text { produtos, líquidos de } \\
\text { subsídios }\end{array}$ & $\begin{array}{c}\text { Produto interno } \\
\text { bruto a preço de } \\
\text { mercado corrente }\end{array}$ & $\begin{array}{c}\text { Cresc. Anual } \\
(\boldsymbol{\%})\end{array}$ \\
\hline 2002 & 22.185 & 4.571 & 26.756 & - \\
2003 & 25.384 & 5.680 & 31.064 & 1,5 \\
2004 & 32.487 & 7.731 & 40.217 & 5,8 \\
2005 & 37.853 & 9.370 & 47.223 & 4,3 \\
2006 & 42.645 & 10.133 & 52.778 & 7,7 \\
2007 & 48.444 & 11.896 & 60.340 & 7,8 \\
\hline
\end{tabular}

Fonte: IBGE, Diretoria de Pesquisas, Coordenação de Contas Nacionais. 
Tabela 3.2: PIB e Valor Adicionado Bruto por Atividade Econômica, 2002-2007

\begin{tabular}{lcccccc} 
& \multicolumn{5}{c}{ Valores correntes em bilhões de reais } \\
\hline \multicolumn{1}{c}{ ATIVIDADES } & $\mathbf{2 0 0 2}$ & $\mathbf{2 0 0 3}$ & $\mathbf{2 0 0 4}$ & $\mathbf{2 0 0 5}$ & $\mathbf{2 0 0 6}$ & $\mathbf{2 0 0 7}$ \\
\hline Atividades Primárias & $\mathbf{1 , 8 1}$ & $\mathbf{2 , 2 1}$ & $\mathbf{3 , 0 4}$ & $\mathbf{3 , 3 2}$ & $\mathbf{4 , 0 5}$ & $\mathbf{4 , 4 9}$ \\
Agricultura, Silvicultura e Exploração Florestal & 1,42 & 1,69 & 2,51 & 2,69 & 3,30 & 3,62 \\
Pecuária e Pesca & 0,38 & 0,52 & 0,53 & 0,63 & 0,75 & 0,86 \\
Atividades Secundárias & $\mathbf{7 , 0 4}$ & $\mathbf{7 , 8 5}$ & $\mathbf{1 0 , 6 4}$ & $\mathbf{1 2 , 7 7}$ & $\mathbf{1 4 , 5 1}$ & $\mathbf{1 6 , 7 0}$ \\
Indústria Extrativa e de Transformação & 5,20 & 6,19 & 8,08 & 9,92 & 11,40 & 12,95 \\
Extrativa Mineral & 1,33 & 1,50 & 2,32 & 3,50 & 4,58 & 5,52 \\
Transformação & 3,87 & 4,69 & 5,76 & 6,42 & 6,81 & 7,43 \\
Construção & 1,66 & 1,38 & 2,21 & 2,53 & 2,63 & 3,26 \\
Prod. e Distr. Eletric. e Água, Esgoto e Limp. Urbana & 0,18 & 0,28 & 0,35 & 0,33 & 0,49 & 0,48 \\
Atividades Terciárias & $\mathbf{1 3 , 3 3}$ & $\mathbf{1 5 , 3 3}$ & $\mathbf{1 8 , 8 1}$ & $\mathbf{2 1 , 7 6}$ & $\mathbf{2 4 , 0 8}$ & $\mathbf{2 7 , 2 6}$ \\
Comércio e Serviços de Reparação e Manutenção & 2,42 & 2,72 & 4,18 & 4,98 & 5,39 & 6,15 \\
Serviços de Alojamento e Alimentação & 0,38 & 0,34 & 0,50 & 0,52 & 0,57 & 0,89 \\
Transporte, Armazenagem e Correio & 1,84 & 1,97 & 2,82 & 3,21 & 3,25 & 3,29 \\
Serviços de Informação & 0,69 & 0,85 & 0,91 & 1,13 & 1,19 & 1,25 \\
Interm. Financeira, Seguros e Prev. Complementar & 0,89 & 1,06 & 1,06 & 1,45 & 1,68 & 1,99 \\
Serviços Prestados a Famílias e Associativos & 0,39 & 0,40 & 0,47 & 0,57 & 0,71 & 0,81 \\
Serviços Prestados a Empresas & 0,67 & 0,76 & 0,91 & 1,02 & 1,29 & 1,44 \\
Atividades Imobiliárias e Aluguel & 2,07 & 2,30 & 2,47 & 2,67 & 2,76 & 3,02 \\
Administração, Saúde e Educação Públicas & 3,15 & 3,83 & 4,36 & 5,16 & 5,73 & 6,78 \\
Saúde e Educação Mercantis & 0,56 & 0,79 & 0,76 & 0,67 & 1,08 & 1,19 \\
Serviços Domésticos & 0,27 & 0,32 & 0,36 & 0,38 & 0,43 & 0,44 \\
Valor Adicionado Bruto a preços básicos & $\mathbf{2 2 , 1 9}$ & $\mathbf{2 5 , 3 8}$ & $\mathbf{3 2 , 4 9}$ & $\mathbf{3 7 , 8 5}$ & $\mathbf{4 2 , 6 4}$ & $\mathbf{4 8 , 4 4}$ \\
Impostos sobre Produtos, Líquidos de Subsídios & 4,57 & 5,68 & 7,73 & 9,37 & 10,13 & 11,90 \\
Produtos Interno Bruto a preços de mercado & $\mathbf{2 6 , 7 6}$ & $\mathbf{3 1 , 0 6}$ & $\mathbf{4 0 , 2 2}$ & $\mathbf{4 7 , 2 2}$ & $\mathbf{5 2 , 7 8}$ & $\mathbf{6 0 , 3 4}$ \\
\hline Produtos
\end{tabular}

Fonte: IJSN, Coordenação de Estudos Econômicos.

\subsection{Mercado de Trabalho}

No que se refere ao mercado de trabalho no Espírito Santo, as taxas de ocupação ${ }^{1}$ das pessoas com 10 anos ou mais de idade, para o período de 2002 e 2007, apresentaram diminuição de $57,8 \%$ para $57,0 \%$, enquanto no Brasil aumentou de 55,7\% para 57,0\%. Contudo, esta diminuição em nível estadual foi acompanhada por um aumento considerável no nível de formalidade. No Espírito Santo, o percentual de trabalhadores formais elevou-se de 39,1\%, em 2002, para 44,9\%, em 2007, enquanto no Brasil os índices foram de $39,8 \%$ para $43,8 \%$, respectivamente.

Os rendimentos médios de todos os trabalhos dos trabalhadores formais no Espírito Santo, de acordo com a Tabela 3, passaram de R \$ 1.153,77, em 2002, para R\$ $1.077,88$, em 2007, registrando uma queda de 6,6\%. No mesmo período, os rendimentos médios dos informais aumentaram em 34,5\%, passando de $\mathrm{R} \$ 477,60$ para $\mathrm{R} \$ 642,54$. Com isso, a média total dos rendimentos cresceu o equivalente a $13,0 \%$, subindo de $\mathrm{R} \$$ 742,73 para $\mathrm{R} \$ 839,17$.

Em relação ao Brasil, observa-se que os trabalhadores formais do Espírito Santo perceberam rendimentos médios inferiores e que se distanciaram ainda mais nesse

1 Indica o percentual da População em Idade Ativa (PIA) em relação à População Economicamente Ativa (PEA).

Econ. e Desenv., Santa Maria, vol. 28, n.2, p. 434 - 452, jul. - dez. 2016 
período. Em 2002, os rendimentos médios do estado representaram 96,2\% daqueles verificados no país, caindo para 89,9\%, em 2007. Enquanto isso, os rendimentos dos trabalhadores informais no estado foram crescentes em relação aos do país, representando 90,6\%, em 2002, e 110,6\%, em 2007.

Resumindo, entre 2002 e 2007, observou-se, ao mesmo tempo, uma diminuição na taxa de ocupação de trabalhadores e um aumento no emprego formal no estado, sendo este acompanhado da diminuição nos rendimentos médios. Por outro lado, a redução proporcional dos trabalhadores informais foi acompanhada do aumento em seus rendimentos médios.

Tabela 3.2.1 - Rendimento médio mensal do trabalho no ES e no Brasil (2002-2007)

\begin{tabular}{lrrrrrr}
\hline \multirow{2}{*}{ Formalidade } & \multicolumn{3}{c}{ Espírito Santo } & \multicolumn{3}{c}{ Brasil } \\
\cline { 2 - 7 } & \multicolumn{1}{c}{$\mathbf{2 0 0 2}$} & $\mathbf{2 0 0 7}$ & Cresc (\%) & \multicolumn{1}{c}{$\mathbf{2 0 0 2}$} & \multicolumn{1}{c}{ 2007 } & Cresc (\%) \\
\hline Formal & $1.153,77$ & $1.077,88$ & $-6,58$ & $1.198,64$ & $1.199,42$ & 0,07 \\
Informal & 477,6 & 642,54 & 34,54 & 527,28 & 581,03 & 10,19 \\
Formal/Informal & 2,42 & 1,68 & - & 2,27 & 2,06 & - \\
Total & $\mathbf{7 4 2 , 7 3}$ & $\mathbf{8 3 9 , 1 7}$ & $\mathbf{1 2 , 9 8}$ & $\mathbf{7 9 4 , 2 8}$ & $\mathbf{8 5 1 , 2 7}$ & $\mathbf{7 , 1 8}$ \\
\hline
\end{tabular}

Fonte: IBGE - PNAD, 2002-2007.

Nota: Os valores foram inflacionados pelo INPC.

Na Tabela 3.2.2 apresenta-se o número de empresas, a quantidade de pessoal ocupado total e assalariado, o tamanho médio e os salários reais anuais médios por atividade econômica no Espírito Santo, em 2007, com destaque para os setores de metalurgia (código 24), o de fabricação de produtos de metal, exceto máquinas e equipamentos (código 25) e o de manutenção, reparação e instalação de máquinas e equipamentos (código 33), mais diretamente ligados ao Projeto CSU, objeto central dessa análise. Cabe destacar que o tamanho médio refere-se à relação existente entre o número de empresas e a quantidade de pessoas ocupadas, ou seja, este é um indicador de empregabilidade nos diversos segmentos, enquanto os salários reais médios referem-se aos rendimentos do pessoal ocupado assalariado.

Segundo esta fonte, em 2007, o Espírito Santo contava com 85,6 mil empresas, sendo a maioria estabelecida na atividade de comércio, reparação de veículos automotores e motocicletas, com 39,2 mil, e na indústria de transformação, com 8,2 mil. A totalidade das empresas foi responsável pela ocupação de 805,6 mil pessoas, sendo 692,1 mil de assalariados ou 85,9\% do total. Observa-se que entre as atividades que se destacaram com maiores tamanhos médios estavam as de administração pública, defesa e seguridade social, com 557,1, e de eletricidade e gás, com 221,5. Enquanto as menores estavam situadas nas atividades de artes, cultura, esporte e recreação, com 3,0, e as atividades profissionais, científicas e técnicas, com 3,5. Cabe destacar que a média do estado foi igual a 9,4 .

No interior da indústria de transformação, o setor de metalurgia contava com 65 empresas, responsáveis por 7.344 pessoas ocupadas, com uma média 113 pessoas por estabelecimento, sendo 7.258 assalariados ou 98,8\% do pessoal total. Nota-se, portanto, um elevado índice de assalariamento neste setor, bem superior à média estadual. $\mathrm{O}$ 
segundo setor em destaque, o de fabricação de produtos de metal, exceto máquinas e equipamentos, contava com 705 empresas, ocupando 7.281 pessoas, sendo 6.280 de assalariados, o que resulta em um tamanho médio de 10,3 pessoas por empresa e um índice de 86,3\% de assalariamento. Por fim, o setor de manutenção, reparação e instalação de máquinas e equipamentos contava com 382 empresas, 5.476 pessoas ocupadas (média de 14,3 pessoas por empresa), sendo 89,2\% de assalariados. É importante frisar que esses três setores da indústria de transformação foram responsáveis por $16,4 \%$ do pessoal total ocupado nesta atividade.

As atividades econômicas que pagaram os maiores salários reais anuais médios foram a de eletricidade e gás $(49.295,50)$ e a de atividades financeiras, de seguros e serviços relacionados $(25.053,80)$. Entre os menores estão o de alojamento e alimentação $(6.290,20)$ e o de artes, cultura, esporte e recreação $(6.935,90)$. A média do estado foi de $13.902,50$.

Tabela 3.2.2 - Número de empresas, pessoal ocupado total e assalariado, tamanho médio e salários reais médios no Espírito Santo (2007)

\begin{tabular}{|c|c|c|c|c|c|}
\hline Atividades Econômicas & Empresas & $\begin{array}{c}\text { Pessoal } \\
\text { total }\end{array}$ & $\begin{array}{l}\text { Tamanho } \\
\text { médio }\end{array}$ & $\begin{array}{c}\text { Pessoal } \\
\text { assalariado }\end{array}$ & $\begin{array}{l}\text { Salários reais } \\
\text { médios* }\end{array}$ \\
\hline Agricultura, pecuária, prod. florestal e pesca & 375 & 9.235 & 24,6 & 8.566 & $9.393,9$ \\
\hline Indústrias extrativas & 873 & 10.053 & 11,5 & 8.452 & $13.727,3$ \\
\hline Indústrias de transformação & 8.184 & 122.936 & 15,0 & 110.772 & $16.616,0$ \\
\hline Metalurgia & 65 & 7.344 & 113,0 & 7.258 & $48.687,2$ \\
\hline Produção de ferro-gusa e de ferroligas & 6 & 630 & 105,0 & 620 & $19.966,1$ \\
\hline Siderurgia & 8 & 4.773 & 596,6 & 4.757 & $57.812,7$ \\
\hline Produção de tubos de aço & 7 & 1.441 & 205,9 & 1.432 & $40.555,2$ \\
\hline Metalurgia dos metais não-ferrosos & 16 & 321 & 20,1 & 299 & $21.739,1$ \\
\hline Fundição & 28 & 179 & 6,4 & 150 & $9.353,3$ \\
\hline Fab. de prod. de metal, exceto máq. e equip. & 705 & 7.281 & 10,3 & 6.280 & $10.872,9$ \\
\hline Fab. de estrut. metálicas e de caldeiraria & 307 & 3.762 & 12,3 & 3.313 & $9.805,3$ \\
\hline $\begin{array}{l}\text { Fab. de tanques, reserv. metálicos e } \\
\text { caldeiras }\end{array}$ & 5 & 700 & 140,0 & 693 & $18.538,2$ \\
\hline Forjaria, estamparia e serv. de trat. de metais & 112 & 1.091 & 9,7 & 925 & $11.180,5$ \\
\hline Fab. art. cutelaria, serralheria e ferramentas & 187 & 884 & 4,7 & 637 & $7.712,7$ \\
\hline Fab. de outros produtos de metal & 94 & 844 & 9,0 & 712 & $10.807,6$ \\
\hline $\begin{array}{l}\text { Manutenção, rep. e instalação de máq. e } \\
\text { equip. }\end{array}$ & 382 & 5.476 & 14,3 & 4.886 & $15.534,4$ \\
\hline Eletricidade e gás & 6 & 1.329 & 221,5 & 1.320 & $49.295,5$ \\
\hline Água, esgoto, resíduos e descontaminação & 150 & 6.341 & 42,3 & 6.159 & $17.505,6$ \\
\hline Construção & 2.620 & 47.196 & 18,0 & 43.281 & $9.149,5$ \\
\hline $\begin{array}{l}\text { Comércio; rep. veíc. automotores e } \\
\text { motocicletas }\end{array}$ & 39.199 & 208.842 & 5,3 & 154.560 & $9.028,0$ \\
\hline Transporte, armazenagem e correio & 2.975 & 53.524 & 18,0 & 49.000 & $12.452,9$ \\
\hline Alojamento e alimentação & 5.064 & 28.531 & 5,6 & 22.070 & $6.290,2$ \\
\hline Informação e comunicação & 1.575 & 9.788 & 6,2 & 7.481 & $17.755,8$ \\
\hline Ativ. financeiras, de seg. e serv. relacionados & 862 & 7.444 & 8,6 & 6.169 & $25.053,8$ \\
\hline Atividades imobiliárias & 450 & 1.873 & 4,2 & 1.140 & $9.274,6$ \\
\hline Atividades profissionais, científicas e técnicas & 3.536 & 12.432 & 3,5 & 7.282 & $13.484,2$ \\
\hline Atividades adm. e serviços complementares & 7.144 & 55.097 & 7,7 & 46.198 & $7.820,9$ \\
\hline Administração pública, defesa e seg. social & 274 & 152.640 & 557,1 & 152.623 & $20.648,8$ \\
\hline Educação & 2.329 & 22.480 & 9,7 & 20.190 & $19.705,0$ \\
\hline Saúde humana e serviços sociais & 2.390 & 25.769 & 10,8 & 21.635 & $10.837,3$ \\
\hline Artes, cultura, esporte e recreação & 1.030 & 3.121 & 3,0 & 1.998 & $6.935,9$ \\
\hline Outras atividades de serviços & 6.534 & 26.963 & 4,1 & 23.173 & $13.638,7$ \\
\hline Total & 85.570 & 805.594 & 9,4 & 692.069 & $13.902,5$ \\
\hline
\end{tabular}

Fonte: IBGE - Cadastro Central de Empresas, 2009.

Nota: *A preços correntes.

Econ. e Desenv., Santa Maria, vol. 28, n.2, p. 434 - 452, jul. - dez. 2016 
As empresas da atividade da indústria de transformação pagaram um salário real anual médio de $\mathrm{R} \$ 16.616,00$. Os maiores salários médios anuais situavam-se nos setores em destaque, sendo que o setor de metalurgia chegou a um montante de $\mathrm{R} \$$ 48.687,20. Cabe destacar que só a indústria siderúrgica capixaba apresentou um tamanho médio igual a 596,6 e um salário médio de $\mathrm{R} \$ 57.812,70$. O setor industrial de produtos de metal, exceto máquinas e equipamentos gerou um salário real anual médio de $\mathrm{R} \$$ 10.872,90, com destaque para a fabricação de tanques, reservatórios metálicos e caldeiras, com salário de $\mathrm{R} \$ 18.538,20$. Por seu turno, o setor de manutenção, reparação e instalação de máquinas e equipamentos gerou um salário médio anual de $\mathrm{R} \$ 15.534,40$.

\section{Estimativas de Impacto}

A seguir são destacados os principais impactos gerados a partir da aplicação da Matriz Insumo-Produto. Nas tabelas 4.1 e 4.2 tem-se o resumo dos impactos gerados no PIB estadual e nacional pelo empreendimento na fase de implantação nos dois cenários (base e agressivo). Cabe destacar que os dois se diferenciam, principalmente, pela maior capacidade da economia capixaba em interagir com o projeto, fornecendo uma quantidade ou uma diversidade maior de insumos e/ou serviços e/ou comprando mais. Porém, observa-se que a diferença nos dois impactos em nível nacional é praticamente nula, dadas a dimensão e a estrutura da economia brasileira, bem como sua capacidade já instalada.

Tabela 4.1 - Cenário base: resumo dos impactos na fase de implantação

\begin{tabular}{clrrrrr}
\hline \multirow{2}{*}{ Ano } & \multirow{2}{*}{ Produção } & \multicolumn{1}{c}{ Base } & \multicolumn{2}{c}{ Impacto } & \multicolumn{2}{c}{ Nova Produção } \\
\cline { 3 - 7 } & & R\$ milhões & R\$ milhões & \multicolumn{1}{c}{$\%$} & R\$ milhões & var \% \\
\hline \multirow{2}{*}{ Ano 1 } & Espírito Santo & 81.433 & 331 & $24,8 \%$ & 81.764 & $0,41 \%$ \\
& Resto do Brasil & 4.194 .511 & 1.006 & $75,2 \%$ & 4.195 .517 & $0,02 \%$ \\
& Brasil & 4.275 .944 & 1.337 & $100,0 \%$ & 4.277 .281 & $0,03 \%$ \\
\hline \multirow{2}{*}{ Ano 2 } & Espírito Santo & 81.433 & 2.357 & $13,5 \%$ & 83.790 & $2,89 \%$ \\
& Resto do Brasil & 4.194 .511 & 15.077 & $86,5 \%$ & 4.209 .587 & $0,36 \%$ \\
& Brasil & 4.275 .944 & 17.434 & $100,0 \%$ & 4.293 .377 & $0,41 \%$ \\
\hline \multirow{2}{*}{ Ano 3 } & Espírito Santo & 81.433 & 484 & $15,6 \%$ & 81.918 & $0,59 \%$ \\
& Resto do Brasil & 4.194 .511 & 2.630 & $84,4 \%$ & 4.197 .141 & $0,06 \%$ \\
& Brasil & 4.275 .944 & 3.115 & $100,0 \%$ & 4.279 .059 & $0,07 \%$ \\
\hline \multirow{2}{*}{ Total } & Espírito Santo & 81.433 & 3.172 & $14,5 \%$ & 84.605 & $3,90 \%$ \\
& Resto do Brasil & 4.194 .511 & 18.713 & $85,5 \%$ & 4.213 .224 & $0,45 \%$ \\
& Brasil & 4.275 .944 & 21.886 & $100,0 \%$ & 4.297 .830 & $0,51 \%$ \\
\hline Fonte: Elaboração própria. & & & & &
\end{tabular}

RE\&D Econ. e Desenv., Santa Maria, vol. 28, n.2, p. 434 - 452, jul. - dez. 2016 
Tabela 4.2 - Cenário agressivo: resumo dos impactos na fase de implantação

\begin{tabular}{llrrrrr}
\hline \multirow{2}{*}{ Ano } & \multirow{2}{*}{ Produção } & \multicolumn{1}{c}{ Base } & \multicolumn{2}{c}{ Impacto } & \multicolumn{2}{c}{ Nova Produção } \\
\cline { 3 - 7 } & & R\$ milhões & R\$ milhões & \multicolumn{1}{c}{$\%$} & R\$ milhões & var \% \\
\hline \multirow{2}{*}{ Ano 1 } & Espírito Santo & 81.433 & 526 & $39,3 \%$ & 81.959 & $0,65 \%$ \\
& Resto do Brasil & 4.194 .511 & 812 & $60,7 \%$ & 4.195 .322 & $0,02 \%$ \\
& Brasil & 4.275 .944 & 1.337 & $100,0 \%$ & 4.277 .281 & $0,03 \%$ \\
\hline \multirow{2}{*}{ Ano 2 } & Espírito Santo & 81.433 & 3.736 & $21,4 \%$ & 85.169 & $4,59 \%$ \\
& Resto do Brasil & 4.194 .511 & 13.698 & $78,6 \%$ & 4.208 .208 & $0,33 \%$ \\
& Brasil & 4.275 .944 & 17.434 & $100,0 \%$ & 4.293 .377 & $0,41 \%$ \\
\hline \multirow{2}{*}{ Ano 3 } & Espírito Santo & 81.433 & 768 & $24,7 \%$ & 82.201 & $0,94 \%$ \\
& Resto do Brasil & 4.194 .511 & 2.346 & $75,3 \%$ & 4.196 .857 & $0,06 \%$ \\
& Brasil & 4.275 .944 & 3.114 & $100,0 \%$ & 4.279 .058 & $0,07 \%$ \\
\hline \multirow{2}{*}{ Total } & Espírito Santo & 81.433 & 5.030 & $23,0 \%$ & 86.463 & $6,18 \%$ \\
& Resto do Brasil & 4.194 .511 & 16.856 & $77,0 \%$ & 4.211 .367 & $0,40 \%$ \\
& Brasil & 4.275 .944 & 21.885 & $100,0 \%$ & 4.297 .829 & $0,51 \%$ \\
\hline
\end{tabular}

Fonte: Elaboração própria.

Assim, as alterações na produção do Espírito Santo nos anos 1, 2 e 3 da fase de instalação, no cenário base, serão iguais a $0,4 \%, 2,9 \%$ e $0,6 \%$, e o total desta etapa a $3,9 \%$. Já na agressiva são $0,7 \%, 4,6 \%$ e $0,9 \%$, com total de 6,2\%. Cabe destacar que as alterações na economia brasileira serão iguais a $0,03 \%, 0,41 \%$ e $0,07 \%$, com total de $0,51 \%$, para ambos os cenários.

O valor bruto da produção representa toda a receita bruta gerada na economia. Com isso, observa-se que cada real investido na fase de implantação do projeto, em nível nacional, trará um retorno de $\mathrm{R} \$ 2,2$ em valor bruto da produção. Já no Espírito Santo será de $\mathrm{R} \$ 1,4$. Esta diferença se deve ao fato da economia brasileira ser mais diversificada e com condições de oferecer serviços mais especializados, com maiores valores ao projeto. Isso se torna evidente na comparação da participação do estado nos valores das compras totais, em relação ao seu impacto no valor bruto da produção, já que enquanto aquele foi de $22,8 \%$, este foi de $14,5 \%$.

Tabela 4.3- Cenário base: Retorno do investimento sobre o Valor Bruto da Produção

\begin{tabular}{lrrr}
\hline \multicolumn{1}{c}{ Itens de impacto } & \multicolumn{1}{c}{ Brasil } & ES & Part. \% do ES \\
\hline Investimento (compras) & $9.923,00$ & $2.258,07$ & 22,8 \\
Impacto VBP & $21.885,88$ & $3.172,31$ & 14,5 \\
Investimento / Impacto VBP & 2,206 & 1,405 & - \\
\hline
\end{tabular}

Fonte: Elaboração própria

Já o valor adicionado é o valor dos bens produzidos por uma economia, depois de deduzidos os custos dos insumos adquiridos de terceiros (matérias-primas, serviços, bens intermediários), utilizados na produção. Desta forma, tem-se que cada real investido do Projeto CSU na fase de implantação trará à economia brasileira um retorno de $\mathrm{R} \$ 0,823$ em valor adicionado, enquanto em nível estadual de R\$ 0,611. Este valor é considerável, já que se trata de um resultado líquido, sem impostos.

Econ. e Desenv., Santa Maria, vol. 28, n.2, p. 434 - 452, jul. - dez. 2016 
Tabela 4.4- Cenário base: Retorno do investimento sobre o Valor Adicionado

\begin{tabular}{lrrr}
\hline \multicolumn{1}{c}{ Itens de impacto } & Brasil & \multicolumn{1}{c}{ ES } & \multicolumn{1}{c}{ Part. \% do ES } \\
\hline Investimento (compras) & $9.923,00$ & $2.258,07$ & 22,8 \\
Impacto VA & $8.162,70$ & $1.380,05$ & 16,9 \\
Investimento / Impacto VA & 0,823 & 0,611 & - \\
\hline
\end{tabular}

Fonte: Elaboração própria.

Para a fase de operação considerou-se a origem dos produtos, tanto para as compras como para as vendas. Desta forma, as alterações entre o cenário base e o agressivo foram pequenas, já que essas alterações ocorreram apenas nos valores para as compras (para as vendas considerou-se produtos integralmente capixabas). Além disso, para o primeiro ano foi considerada a utilização de $85 \%$ da capacidade instalada da siderúrgica (cujo valor de impacto total encontra-se no segundo ano de operação). Observa-se que o Espírito Santo receberá 45,4\% dos impactos no cenário base e 46,0\% no agressivo. Por isso, as alterações na economia capixaba no primeiro e no segundo ano de operação serão iguais a 8,3\% e 9,8\% para o cenário base e iguais a 8,4\% e 9,9\% para o agressivo, sendo que o impacto total na economia brasileira será de $0,4 \%$ em ambos os casos.

Tabela 4.5 - Cenário base: resumo dos impactos da fase de operação

\begin{tabular}{clrrrrr}
\hline \multirow{2}{*}{ Ano } & \multirow{2}{*}{ Produção } & \multicolumn{1}{c}{ Base } & \multicolumn{2}{c}{ Impacto } & \multicolumn{2}{c}{ Nova Produção } \\
\cline { 3 - 7 } & & R\$ milhões & R\$ milhões & \multicolumn{1}{c}{$\%$} & R\$ milhões & \multicolumn{1}{c}{ var } \\
\hline \multirow{2}{*}{ Ano 1 } & Espírito Santo & 81.433 & 6.742 & $45,44 \%$ & 88.175 & $8,28 \%$ \\
& Resto do Brasil & 4.194 .511 & 8.094 & $54,56 \%$ & 4.202 .605 & $0,19 \%$ \\
& Brasil & 4.275 .944 & 14.836 & $100,00 \%$ & 4.290 .780 & $0,35 \%$ \\
\hline \multirow{2}{*}{ Ano 2 em } & Espírito Santo & 81.433 & 7.932 & $45,44 \%$ & 89.365 & $9,74 \%$ \\
diante & Resto do Brasil & 4.194 .511 & 9.522 & $54,56 \%$ & 4.204 .033 & $0,23 \%$ \\
& Brasil & 4.275 .944 & 17.454 & $100,00 \%$ & 4.293 .398 & $0,41 \%$ \\
\hline
\end{tabular}

Fonte: Elaboração própria.

Tabela 4.6 - Cenário agressivo: resumo dos impactos da fase de operação

\begin{tabular}{clrrrrr}
\hline \multirow{2}{*}{ Ano } & \multirow{2}{*}{ Produção } & \multicolumn{1}{c}{ Base } & \multicolumn{2}{c}{ Impacto } & \multicolumn{2}{c}{ Nova Produção } \\
\cline { 3 - 7 } & & R\$ milhões & R\$ milhões & \multicolumn{1}{c}{$\%$} & R \$ milhões & \multicolumn{1}{c}{ \%ar } \\
\hline \multirow{2}{*}{ Ano 1 } & Espírito Santo & 81.433 & 6.819 & $45,96 \%$ & 88.252 & $8,37 \%$ \\
& Resto do Brasil & 4.194 .511 & 8.017 & $54,04 \%$ & 4.202 .528 & $0,19 \%$ \\
& Brasil & 4.275 .944 & 14.836 & $100,00 \%$ & 4.290 .780 & $0,35 \%$ \\
\hline \multirow{2}{*}{ Ano 2 em } & Espírito Santo & 81.433 & 8.023 & $45,96 \%$ & 89.456 & $9,85 \%$ \\
diante & Resto do Brasil & 4.194 .511 & 9.432 & $54,04 \%$ & 4.203 .942 & $0,22 \%$ \\
& Brasil & 4.275 .944 & 17.454 & $100,00 \%$ & 4.293 .398 & $0,41 \%$ \\
\hline
\end{tabular}

Fonte: Elaboração própria.

O retorno de cada real investido no Valor Bruto da Produção do Projeto CSU, em nível nacional, será de R \$2,3. Já no Espírito Santo será R \$ 1,4. Da mesma forma que ocorreu na fase de implantação, esta diferença se deve pelas melhores condições da economia brasileira em fornecer serviços mais especializados, ou seja, com maiores valores. Tal fato fica evidente na comparação da participação do estado nos valores das 
compras totais, em relação ao seu impacto no Valor Bruto da Produção, já que enquanto aquele será de $76,5 \%$, este será de 45,4\%.

Tabela 4.7- Cenário base: Retorno do investimento sobre o Valor Bruto da Produção

\begin{tabular}{lrrr}
\hline \multicolumn{1}{c}{ Itens de impacto } & Brasil & ES & Participação \% do \\
\hline Investimento (compras e vendas) & $7.586,88$ & $5.804,70$ & 76,5 \\
Impacto VBP & $17.454,39$ & $7.931,98$ & 45,4 \\
Investimento / Impacto VBP & 2,301 & 1,366 & - \\
\hline Fonte: Elaboração própria. & & &
\end{tabular}

O retorno no Valor Adicionado é de R\$ 0,805 na economia brasileira e de R\$ 0,408 na capixaba. A diferença entre a participação do estado no Valor Bruto de Produção e no Valor Agregado se deve ao fato de esta ser uma economia pouco diversificada. Esta situação pode se alterar com a instalação de empreendimentos com alta capacidade de agregar valor.

Tabela 4.8- Cenário base: Retorno do investimento sobre o Valor Adicionado

\begin{tabular}{lrrr}
\hline \multicolumn{1}{c}{ Itens de impacto } & Brasil & ES & Participação \% \\
\hline Investimento (compras e vendas) & $7.586,88$ & $5.804,70$ & 76,5 \\
Impacto VA & $6.105,42$ & $2.368,33$ & 38,8 \\
Investimento / Impacto VA & 0,805 & 0,408 & - \\
\hline Fonte: Elaboração própria. & & &
\end{tabular}

A seguir têm-se os efeitos do empreendimento na economia capixaba, caso esta seja "congelada" no ano de 2003, ou seja, as oscilações provocadas posteriormente ao início serão desencadeadas direta e indiretamente pelo Projeto CSU. Com isso, tem-se que no auge da implantação a economia capixaba estará operando com $2,7 \%$ ou $4,3 \%$ a mais que o inicial (dependendo do cenário, base ou agressivo, respectivamente), e na fase de operação estes chegarão a $6,5 \%$ ou $6,6 \%$.

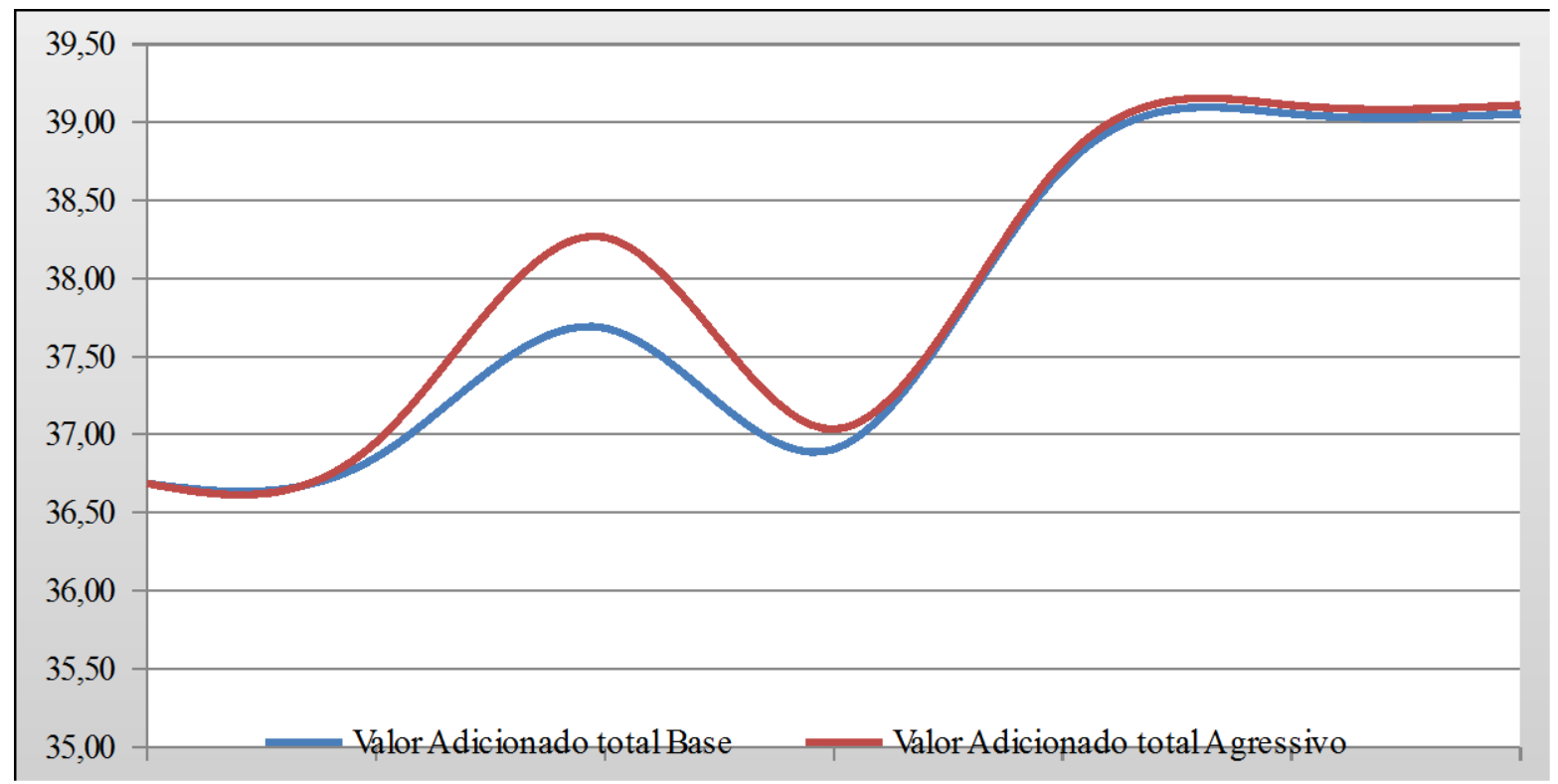

Figura 4.1 - Valor adicionado total da economia, em bilhões de R\$

Econ. e Desenv., Santa Maria, vol. 28, n.2, p. 434 - 452, jul. - dez. 2016 
Com base na projeção do PIB realizada pelo Plano de Desenvolvimento do Espírito Santo, intitulado ES 2025, observa-se que caso a economia opere sem a CSU, a sua taxa geométrica média de crescimento será de 5,69\%. Já com a empresa operando no cenário base, esta será de 5,75\%, enquanto no agressivo será de 5,7611\%.

Tabela 4.9 - Taxa geométrica de crescimento entre 2010/2030 com e sem a CSU

\begin{tabular}{lc}
\hline \multicolumn{1}{c}{ Item } & Taxa geométrica de crescimento médio (\%) \\
\hline PIB a preços de 2007 & 5,6905 \\
PIB com CSU - Cenário Base (R\$ 2007) & 5,7595 \\
PIB com CSU - Cenário Agressivo (R\$ 2007) & 5,7611 \\
\hline
\end{tabular}

Fonte: ES 2025, 2006

Na tabela a seguir tem-se um comparativo do pessoal ocupado total e assalariado gerados pela CSU. Desta forma, percebe-se que a capacidade de geração de emprego total na fase de implantação é superior à fase de operação. Na implantação serão gerados 21,4 mil empregos assalariados e 28,0 mil totais. Já na operação, 18,1 mil e 21,5 mil, respectivamente. Observa-se também que a estimativa apresentada para o salário anual médio gerado pelo empreendimento na fase de operação será superior à de implantação. Isso se relaciona ao maior nível educacional dos empregados daquela etapa e, portanto, o maior rendimento, já que tal relação é diretamente proporcional e amplamente discutida na literatura.

Tabela 4.10 - Impactos totais no mercado de trabalho na implantação e na operação

\begin{tabular}{lcc}
\hline \multicolumn{1}{c}{ Item } & Implantação & Operação \\
\hline Pessoal ocupado total (unid) & 28.057 & 21.541 \\
Pessoal ocupado assalariado (unid) & 21.413 & 18.091 \\
Salários anuais médios (R\$) & 13.173 & 29.452 \\
\hline
\end{tabular}

Fonte: Elaboração própria.

Desta forma, ao se comparar os salários gerados pelo empreendimento com a média recebida no município de Anchieta e no Espírito Santo, tem-se o baixo valor apresentado na fase de implantação, em relação ao que é pago em média no município e no estado. Porém, para a estimativa apresentada na fase de operação, o resultado é quase o dobro das médias apresentadas por ambos.

Tabela 4.11 - Salário anual médio, em 2007 - em preços correntes

\begin{tabular}{lcc}
\hline & Regiões & $\mathbf{2 0 0 7}$ \\
\hline Anchieta & $15.817,92$ \\
Espírito Santo & $15.194,52$ \\
\hline
\end{tabular}

Fonte: MTE, 2007.

Para o caso da estimativa de ISS na fase de implantação, não foi possível utilizar o modelo adotado como padrão neste trabalho, por ela se considerar uma etapa diferenciada, com maior proporção de serviços. Em função disso, para tal estimativa utilizou-se a alíquota de arrecadação do estado, que é de 5\%. Portanto, tem-se que na fase de implantação serão gerados, ao todo, R \$ 201,3 milhões em ISS no Espírito Santo.

Para a fase de implantação, como é uma etapa comum, ponderou-se a arrecadação do estado em 2003 pelo Valor Bruto da Produção por setor da economia. Com base nisso, chegou-se na estimativa de que serão arrecadados 15,3 milhões no cenário base e 18,0 
milhões no agressivo. Apenas para efeitos de comparação, a arrecadação deste imposto em Anchieta foi de R \$ 25,2 milhões em 2007 (cabe destacar que neste ano estava sendo construída a terceira usina de pelotização da Samarco) e no estado foi de R $\$ 529,8$ milhões.

\section{Considerações Finais}

À guisa de conclusões, podem ser destacados três pontos fundamentais em relação aos impactos do Projeto CSU. Em primeiro lugar, há que se ressaltar o poder que exerce uma usina siderúrgica, tanto na localidade de sua instalação quanto em seu entorno, chegando mesmo a atingir os mercados mundiais. Esse poder se traduz pelo grande volume de materiais e produtos movimentados por uma siderúrgica, haja vista que a unidade básica é sempre medida em toneladas, e pela sua logística peculiar, que resulta em construção de estradas de ferro, de estradas de rodagem, de portos, etc., que acabam se constituindo em um capítulo à parte quando considerados os seus impactos.

Em paralelo, uma siderúrgica é responsável por um grande volume, e uma correspondente variedade, de compras de bens e serviços, envolvendo uma enorme utilização de parceiros, o que contribui para ampliar a circulação monetária e para reforçar a especialização e a divisão do trabalho. Com isso, são criadas as condições para a existência de um verdadeiro cluster de negócios em seu redor, com participação de pequenas e médias empresas, que se aproveitam da difusão de externalidades, uma vez que, sendo sua competitividade basicamente amparada nos custos reduzidos de produção, a eficiência produtiva deve se propagar para todos os participantes da cadeia produtiva. Do mesmo modo, podem ser entendidas as vendas de co-produtos, aqueles gerados durante o processo produtivo do aço, capazes de dinamizar outros ramos produtivos, como a produção de cimento, bem como a geração de energia elétrica para além das necessidades da usina.

Por fim, ainda nas considerações sobre o poder de uma usina, não se pode deixar de mencionar o elevado volume de empregos diretos gerados e os correspondentes salários pagos, que representam um expressivo volume de poder de compra local, além do fato notório de que a siderurgia é responsável pelos maiores salários médios dentre os setores produtivos. A qualificação e a escolaridade mínima exigida também representa um impacto positivo para a sociedade capixaba, tanto do ponto de vista da proliferação de instituições de ensino quanto da elevação média da escolaridade que poderá repercutir em outros ramos de negócios.

Em segundo lugar, a instalação da CSU no Espírito Santo vem reforçar um APL ou um cluster já bastante consolidado no estado, haja vista as quase três décadas passadas desde o surgimento da CST, atual ArcelorMittal Tubarão, que foi construindo uma curva de aprendizado tanto com fornecedores locais quanto com a qualificação dos recursos humanos. Aliada à existência de outros grandes projetos em solo capixaba - Vale, Fibria, Samarco Mineração - foi construída uma verdadeira rede de fornecedores locais, altamente especializados e capacitados, incluindo expressivas instituições, como o IELES e a Findes - protagonizadoras da criação do Prodfor, um programa de desenvolvimento de fornecedores, criado em 1996.

Em terceiro, a instalação da CSU no município de Anchieta está em consonância com o objetivo de interiorização do desenvolvimento capixaba, proposto no Plano de

Econ. e Desenv., Santa Maria, vol. 28, n.2, p. 434 - 452, jul. - dez. 2016

RE\&D 
Desenvolvimento ES 2025. Além da sinergia com a rede de fornecedores já existentes no estado, esse Projeto certamente criará impulsos para a geração de novas atividades empresariais na região sul do estado, contribuindo para o desenvolvimento das cidades e para a geração de emprego e renda locais.

\section{REFERÊNCIAS BIBLIOGRÁFICAS}

AEQUUOS CONSUlTORIA. Finanças dos Municípios Capixabas. 2008. Disponível em: <http://www.financasdosmunicipios.com.br>. Acesso em 20 dez. 2009.

DE PAULA, G. M. Competitividade da Siderurgia Brasileira. Apresentação. Março de 2010

FEIJÓ, C.A; RAMOS, R.L.O. Contabilidade social: a nova referência das Contas Nacionais do Brasil. 3 ed. Rio de Janeiro: Editora Elsevier, 2007. 325 p.

FUNDAÇÃO GETÚlIO VARGAS - FGV. Salário mínimo convertido para Real. Disponível em: <http://www.fgvdados.fgv.br/bf/dsp_consulta.asp>. Acesso em: $20 \mathrm{dez}$. 2009.

INSTITUTO AÇO BRASIL - IABr. Números de Mercado: Estatísticas. Disponível em <www.acobrasil.org.br>. Acesso em 20 dez. 2009.

INSTITUTO BRASILEIRO DE GEOGRAFIA E ESTATÍSTICA - IBGE. Pesquisa Nacional por Amostra de Domicílios: microdados. Rio de Janeiro, 2002 e 2007. 2 CDROM.

Matriz de Insumo-Produto: Brasil. 2000/2005. Rio de Janeiro, 2008. 57 p. Disponível em: <http://www.ibge.gov.br>. Acesso em 20 nov. 2009.

. Cadastro Central de Empresas. Disponível em: <www.ibge.gov.br〉. Acesso em: 20 dez. 2009.

. Índice de Preços ao Consumidor Amplo - IPCA. Disponível em: <www.ibge.gov.br>. Acesso em: 20 dez. 2009.

INSTITUTO JONES DOS SANTOS NEVES - IJSN. Produto Interno Bruto Municipal. 2002-2007. Disponível em: 〈http://www.ijsn.es.gov.br>. Acesso em 20 dez. 2009.

KURESKI, R.; NUÑEZ, B.C; RODRIGUES, R. L. Multiplicadores de emprego e renda da indústria brasileira de celulose, papel e gráfica em 2003: uma aplicação da matriz de insumo-produto. In: Anais do Congresso Brasileiro de Economia e Sociologia Rural, 45, 2007, Londrina-PR: SOBER, 2007. 19 p.

MINISTÉRIO DO TRABALHO E EMPREGO - MTE. Anuário estatístico RAIS. Disponível em: <http://anuariorais.caged.gov.br/>. Acesso em: 20 dez. 2009a. 
Cadastro Geral de Empregados e Desempregados - CAGED. Disponível em: <http://estatistica.caged.gov.br/>. Acesso em: 20 dez. 2009 b.

MORANDI, Angela Maria. Na mão da história: a CST na siderurgia mundial. Vitória: Edufes, 1997.

OLIVERIA, V. C. P. Relatório Setorial da Siderurgia. FINEP, 2007

Econ. e Desenv., Santa Maria, vol. 28, n.2, p. 434 - 452, jul. - dez. 2016 